\title{
MUCOADHESIVE BUCCAL PATCHES OF LORNOXICAM: II- IN-VIVO EVALUATION AND CLINICAL EFFICACY
}

Fawzia Habib $^{1}$, Salah El-Dein Shaltout ${ }^{2}$, Maha Abdel Azeem ${ }^{1}$, Gihan Fetih ${ }^{1}$ and Mohamed Safwat $^{1}$

${ }^{1}$ Department of Pharmaceutics, Faculty of Pharmacy, Assiut University, Assiut, Egypt

${ }^{2}$ Department of Surgery, Faculty of Medicine, Assiut University, Assiut, Egypt

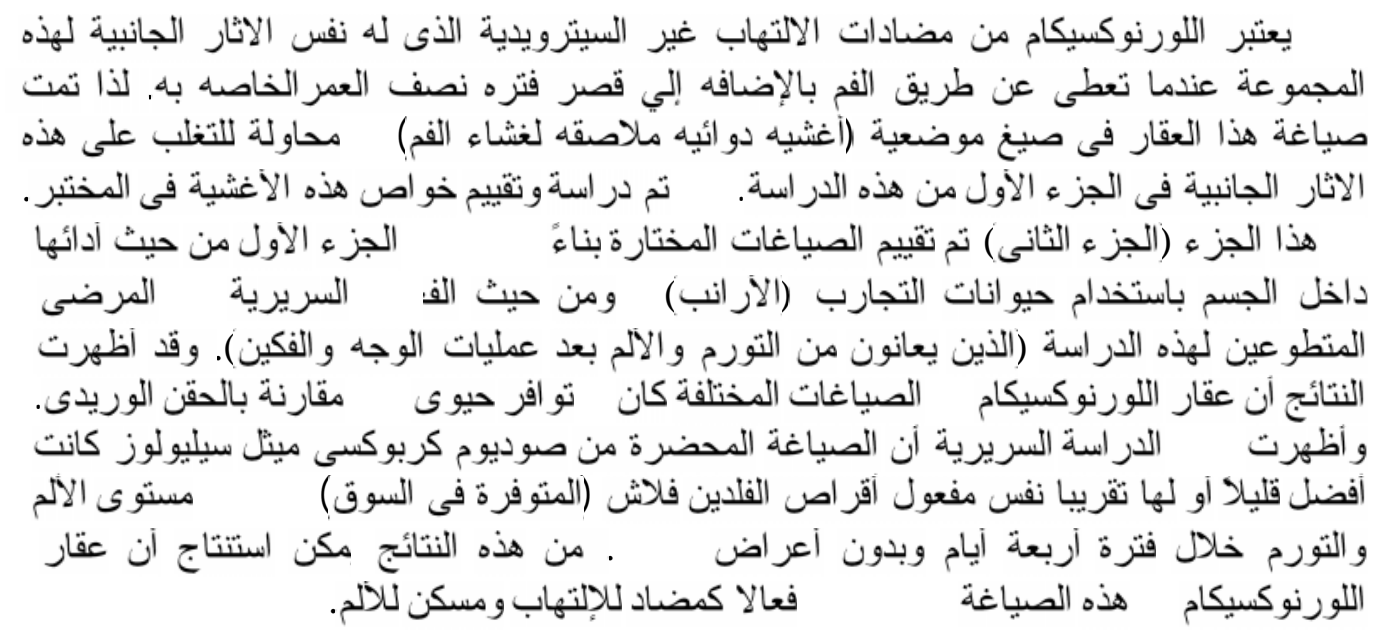

Lornoxicam is a NSAID of the oxicam class and it has the same side effects of this group when taken orally. In attempts to avoid the systemic side effects of lornoxicam (e.g. gastric irritation) and to achieve sustained release of the drug, several buccal patch formulations containing lornoxicam were prepared using different polymers and were evaluated for in-vitro characteristics in part I of this study. In the current study, the selected formulations (based on the previous in-vitro data) are evaluated for in-vivo performance using experimental animals and clinical efficacy on human volunteers. Pharmacokinetic parameters were assessed following application of the selected patches in rabbits. A comparative clinical study was conducted on patients with post-operative pain and edema following maxillofacial operations. The results of the in-vivo animal experiment showed that lornoxicam formulated in different buccal patches was successfully delivered to the systemic circulation and showed high absolute bioavailability of lornoxicam. The clinical study results revealed that sodium carboxy methyl cellulose (NaCMC, 3\%) formulation applied to the buccal mucosa was slightly better or equally effective to the orally administered commercial oxicam product (Feldene Flash ${ }^{\circledR}$ tablets) in reducing pain level, swelling and tenderness within a period of 4 days with no observed side effects. These findings suggest that lornoxicam administered in this buccal patch may present a potential therapeutic use as a strong anti-inflammatory and analgesic agent.

\section{INTRODUCTION}

In oral transmucosal drug delivery, drugs are directly exposed to the oral (buccal and sublingual) mucosa and permeate across the mucosal tissues to reach the systemic circulation. There are many reports ${ }^{1-5}$ on the buccal drug delivery because it offers many advantages over peroral delivery including abundant blood supply, robustness of the epithelium, facile removal of the dosage form in case of need, satisfactory patient compliance and improved bioavailability due to avoidance of degradation in the gastrointestinal tract (GIT) and hepatic first-pass metabolism ${ }^{6}$.

However, most drugs in the term of buccal or sublingual tablets have exhibited low bioavailabilities due to the low mucosal 
membrane permeability and relatively small surface area available for absorption ${ }^{7 \& 3}$. The permeation enhancement approach was considered in order to further improve buccal mucosal membrane permeability of various drug delivery systems ${ }^{3 \& 8-10}$.

Buccal patches are highly flexible and thus much more readily tolerated by the patient than tablets. Patches also ensure more accurate dosing of the drug compared to gels and ointments ${ }^{11}$.

Lornoxicam is a member of the oxicam class of non steroidal anti-inflammatory drugs (NSAIDs) with analgesic, anti-inflammatory and antipyretic properties. It is available in oral and parenteral formulations. It is absorbed rapidly and almost completely from the gastrointestinal tract. Although the usual oral dose of (4-8) $\mathrm{mg}$ of lornoxicam is well tolerated by the patients, yet several side effects have been reported including: stomach pains, nausea, vomiting, dizziness, somnolence, drowsiness, headache and flushing ${ }^{12}$. In addition to the gastrointestinal adverse effects, it binds extensively to plasma albumin (99\%), and has a relatively short plasma half-life (3 to $5 \mathrm{hrs})^{13}$ which makes it a good candidate for local delivery via sustained release dosage forms.

The aim of the present study was to investigate the efficacy of buccal administration of lornoxicam from the buccal patches developed in our previous study ${ }^{14}$. The investigation involved two steps: (a) evaluation of the pharmacokinetics of the drug using rabbits as experimental animals, and (b) a comparative clinical evaluation of the analgesic and anti-inflammatory effectiveness of the buccal dosage form of lornoxicam versus a commercial product (Feldene Falsh ${ }^{\circledR}$ tablets) in patients with post-operative pain and edema following maxillofacial operations. Feldene Flash $^{\circledR}$ was selected for comparison because it can be administered orally or sublingually and piroxicam belongs to the same class of lornoxicam (oxicams), so it was the closest available product for comparison to buccal lornoxicam. In addition, it was the NSAID routinely used in the unit of maxillofacial surgery, Assiut University Hospital.

\section{EXPERIMENTAL}

\section{Materials}

Lornoxicam was purchased from Chema Pharm, Egypt. Hydroxypropylmethyl cellulose (HPMC), Hydroxyethyl cellulose (HEC), Sodium carboxy methyl cellulose (NaCMC) and sodium alginate (Dow Chemical Co. USA). Propylene glycol (El-Nasr Chemical Co., Cairo, Egypt). All solvents used in HPLC analysis were of HPLC grade, (Merck, Darmstadt, Germany). All other materials were of analytical grade. Double distilled water was used for preparing solutions.

\section{Methods}

\section{In-vivo study design}

Twelve adult rabbits weighing 2-2.5 kg were obtained from Assiut University animal house. All experimental animals were individually housed in a loose box, and were fed twice a day with balanced ration and given water and libitum. The rabbits were divided into 4 groups. The first 3 groups of animals received mucoadhesive buccal patches $(1 \mathrm{~cm} \times$ $2.5 \mathrm{~cm})$ containing $2 \mathrm{mg}$ lornoxicam. The patches were prepared using solvent casting method of solutions containing lornoxicam $(0.1 \% \mathrm{w} / \mathrm{v})$ and propylene glycol $(30 \% \mathrm{w} / \mathrm{v})$ as an enhancer and either sodium alginate $4 \% \mathrm{w} / \mathrm{v}$ [formulation 1], mixture of hydroxyl propyl methyl cellulose (HPMC) 2\% w/v and hydroxyl ethyl cellulose (HEC) $2 \%$ w/v [formulation 2], or sodium carboxy methyl cellulose (NaCMC) 3\% w/v [formulation 3]. Composition of polymer solutions used for patch formulations is shown in table 1 . The fourth group of animals received $2 \mathrm{mg}$ of lornoxicam intravenously $\left(\mathrm{Xefo}^{\circledR}{ }^{\circledR}\right.$ vial, October Pharma, Egypt).

Blood samples $(2 \mathrm{ml})$ were withdrawn from the rabbits into heparinized tubes at the following time points: pre-dose, 0.5, 1, 2, 4, 6 and $8 \mathrm{hrs}$ following drug administration.

The plasma was obtained by centrifugation at $1500 \mathrm{rpm}$ for 15 min within 1 $\mathrm{hr}$ of collection (Laboratory centrifuge, Hernle Z-230, BHG, Hamburg, Germany). Plasma samples were stored at or below $-20^{\circ} \mathrm{C}$. 
Table 1: Composition of lornoxicam buccal patches - forming solution.

\begin{tabular}{||c|lc||}
\hline Formula & \multicolumn{2}{|c|}{ Composition (\%w/v) } \\
\hline & Lornoxicam & 0.1 \\
& Sod alginate & 4.0 \\
Formulation 1 & Glycerol & 5.0 \\
& Propylene glycol & 30 \\
& Alkalinized water to & 100 \\
\hline & Lornoxicam & 0.1 \\
& HEC & 2.0 \\
Formulation 2 & HPMC & 2.0 \\
& Glycerol & 5.0 \\
& Propylene glycol & 30 \\
& Alkalinized water to & 100 \\
\hline & Lornoxicam & 0.1 \\
& Na CMC & 1.0 \\
Formulation 3 & Glycerol & 5.0 \\
& Propylene glycol & 30 \\
& Alkalinized water to & 100 \\
\hline
\end{tabular}

Alkalinized water: $5 \mathrm{ml}$ of $0.15 \mathrm{~N} \mathrm{NaOH} / 100$ ml water.

\section{Preparation of standard solutions}

Lornoxicam stock standard solution was prepared by weighing lornoxicam $(50 \mathrm{mg})$ into a 100-ml flask and dissolving in $0.25 \mathrm{ml}$ of 0.2 $\mathrm{M} \mathrm{NaOH}$ and $0.625 \mathrm{ml}$ of water. This solution was then diluted with water to a final volume of $100 \mathrm{ml}$.

Plasma standards for the calibration curve were prepared by adding appropriate volumes from the stock solution to drug-free plasma to obtain final concentrations equivalent to 0.1 , $0.2,0.5,1$ and $2 \mu \mathrm{g} / \mathrm{ml}$ and stored at $-20^{\circ} \mathrm{C}$ until assay.

\section{Plasma extraction ${ }^{15}$}

$200 \mu \mathrm{l}$ of blank plasma and calibration standards were mixed with $200 \mu \mathrm{l}$ of $0.5 \mathrm{M}$ $\mathrm{HCl}$. The samples were extracted with $900 \mu \mathrm{l}$ of ethyl acetate in $2.0 \mathrm{ml}$ polypropylene tubes by vortex-mixing for $5 \mathrm{~min}$ at high speed and centrifuged at $5000 \mathrm{rpm}$ for $5 \mathrm{~min}$ at room temperature (Laboratory centrifuge, Hernle Z230, BHG, Hamburg, Germany).

$800 \mu \mathrm{l}$ of the organic layer was transferred and evaporated to dryness using vacuum concentrator at $30^{\circ} \mathrm{C}$. The residues were dissolved in $40 \mu \mathrm{l}$ of the mobile phase by vortex-mixing for $2 \mathrm{~min}$, centrifuged at 5000 rpm for 5 min and injected into the HPLC column.

\section{Analysis of plasma samples ${ }^{16}$}

Plasma samples were analyzed for intact lornoxicam by HPLC. The HPLC system consisted of: a Knauer Model K-500 solvent delivery pump (Berlin, Germany), injector valve with a 501 loop, the column used was Aqua RP-C ${ }_{18}$ column $(250$ x $4.6 \mathrm{~mm}$ internal diameter, $5 \mathrm{~m}$ particle diameter), (phenomenex, USA) and a precolumn (guard column with $\mathrm{C}_{18}$ precolumn inserts) (Waters, USA), a Knauer Model K-2500 UV variable wave length detector (Berlin, Germany), the chromatograms were recorded and processed on Shimadzu Model C- R6A chromatopac integrator (Kyoto, Japan), the eluent was filtered through a $0.45 \mathrm{~m}$ membrane filter (Gelman instrument Co.) using vacuum filtration unit (phenomenex, USA).

501 aliquots were injected (triplicate) and eluted with a mobile phase consisted of methanol: acetonitrile: acetate buffer, $\mathrm{pH} 4.6$ (4.5: 0.5: 5.0, v/v/v). The flow rate was set at $1.0 \mathrm{ml} \mathrm{min}{ }^{-1}$ and the eluent was monitored at $280 \mathrm{~nm}$. Figure 1 shows representative typical chromatograms of rabbit blank plasma and plasma obtained from the animal after buccal administration of $2 \mathrm{mg}$ lornoxicam.

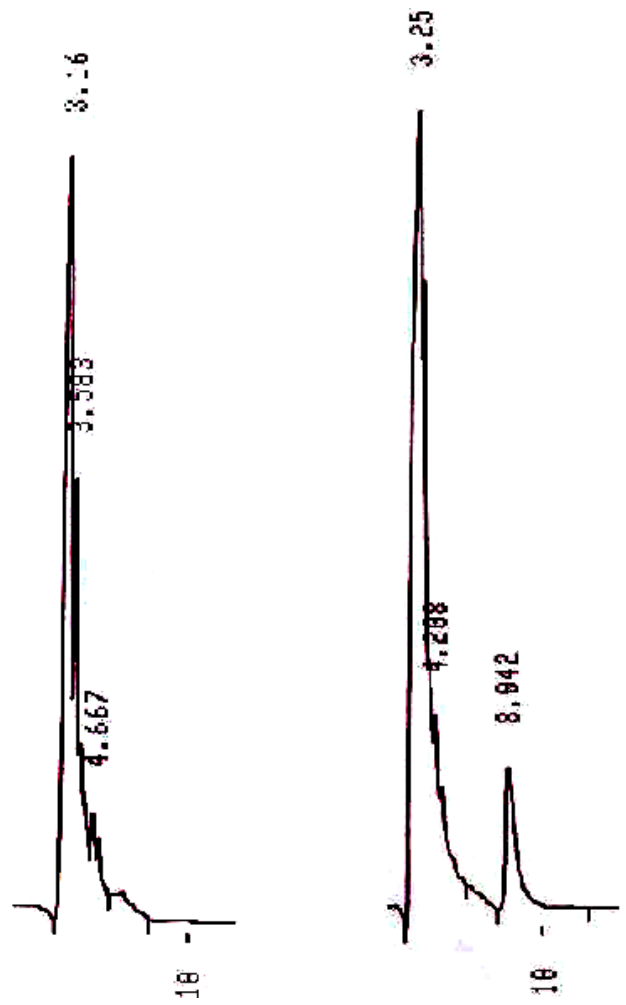

Fig. 1: Typical chromatograms of: (A): Rabbit blank plasma, (B): Plasma obtained from the animal after buccal administration of 2 mg lornoxicam. 


\section{Pharmacokinetic analysis (data analysis)}

After measuring lornoxicam concentration in plasma, lornoxicam pharmacokinetic parameters were assessed by fitting the plasma concentration-time data to the suitable model using WinNonlin ${ }^{\mathrm{TM}}$ standard version 1.5 (Science Consulting, Apex, NC, USA) software. Ordinary least squares sum was used as a criterion function in the fitting process. Goodness of fit was estimated by visual inspection of the fitted curve and correlation coefficient, which exceeded 0.95 .

Absorption rate constant $\left(\mathrm{K}_{\mathrm{a}}\right)$, absorption half-life $\left(\mathrm{t}_{1 / 2 \mathrm{a}}\right)$, elimination rate constant $\left(\mathrm{K}_{\mathrm{el}}\right)$, elimination half-life $\left(t_{1 / 2}\right)$, area under the plasma lornoxicam concentration versus time curve (AUC) and clearance divided by the bioavailability fraction $(\mathrm{Cl} / \mathrm{F})$ were calculated according to conventional algorithms. Maximum concentration $\left(\mathrm{C}_{\max }\right)$ and time to reach maximum concentration $\left(\mathrm{T}_{\max }\right)$ were reported as observed.

The kinetic parameters of lornoxicam in plasma were derived for individual animals. The average values for these parameters were then calculated. All data are presented as mean \pm SD. Statistical analysis of the obtained results was carried out by the Student's $t$-test.

\section{Clinical evaluation}

This part of the study was performed in the unit of maxillofacial surgery, Assiut University Hosptial. The study obtained approval of the Ethical Review Board of Assiut Faculty of Medicine.

Forty patients were included in this study. The average age was 30 years. Each formulation was tested on a group of 10 patients to demonstrate the efficacy on postoperative pain and edema following maxillofacial operations.
Operations were either minor or major. Minor operations included cyst, simple fracture, cut inucosal wounds, epulides (gum swelling) and cheek polybs. Major operations included fracture mandible, fracture maxilla, glossectomy, mandibulectomy and cleft palate. In these major operations, a single parenteral dose $(50 \mathrm{mg})$ of Pethidine ${ }^{\circledR}$ was given to control the immediate post-operative pain (in the first 1-2 hrs).

Each patient received a single patch $(1 \mathrm{~cm}$ $\times 5 \mathrm{~cm}$ ) containing $4 \mathrm{mg}$ of lornoxicam immediately after the operation (day-1) and then daily for the next three days.

For comparison, another group of 10 patients were given Feldene Flash $^{\circledR}$ tablets (Pfizer, Egypt) sublingually (1 tablet, containing $20 \mathrm{mg}$ piroxicam) according to the same regimen.

Clinical assessments were made $4 \mathrm{hrs}$ after application of the first dose and then daily on the same time of the second, third and fourth days.

The following parameters were utilized during the study period:

1- Spontaneous pain: was assessed using a visual analogue scale (Fig. 2) ${ }^{17}$ ranged from 0 (no pain) to 10 (the worst pain imaginable). The patients were asked by the investigator to describe the degree of pain they had experienced.

2- Tenderness: was assessed by the investigator using a 4-point rating scale (none, mild, moderate, severe).

3- Swelling: was assessed by the investigator. The degree of swelling was measured in the four study days and in the pre-operative day (day-0) by measuring the thickness of edema using vernier caliper.

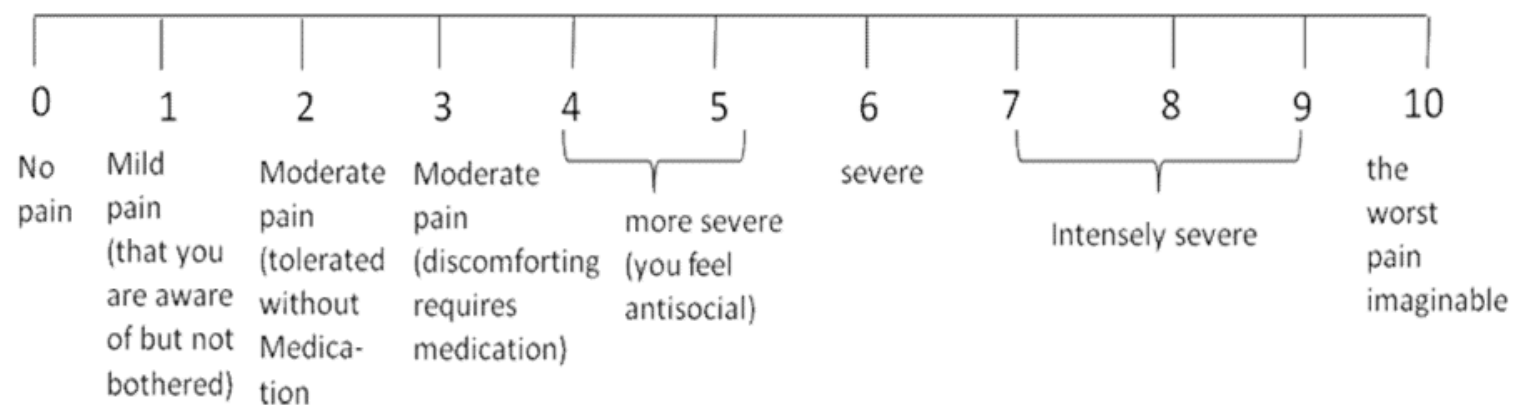

Fig. 2: Visual analogue scale. 
Patients were also assessed at each visit to the occurrence of side effects.

For statistical comparisons between treatments, the means were subjected to the least significant difference (LSD) test to evaluate mean differences in clinical recordings. The analysis of variance (ANOVA) was also applied to test the pain score and swelling variability with time. The level of significance was set at $5 \%$.

\section{RESULTS AND DISCUSSION}

\section{Pharmacokinetic parameters}

Based on the measured concentrations of lornoxicam in rabbits' plasma, individual concentration-time profiles following single buccal and I.V. administrations of $2 \mathrm{mg}$ lornoxicam were constructed. Concentration time courses in plasma were presented (Fig. 3).

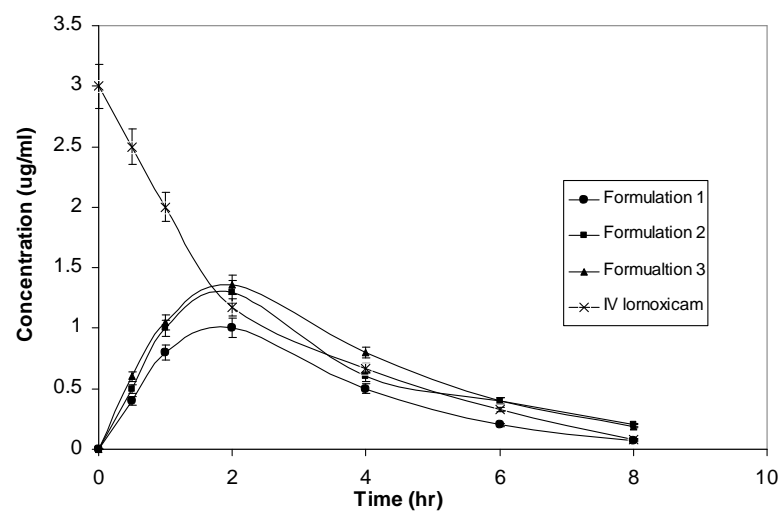

Fig. 3: Lornoxicam concentration profile (mean) in plasma of rabbit after administration of different lornoxicam formulations.

The plasma concentration versus time data after buccal and I.V. administrations could best be described by a one-compartment model with first-order absorption and elimination. The data were fit to a one-compartment model of the format:

$\mathrm{C}=\mathrm{A}\left(\mathrm{e}^{-\mathrm{kelt}}-\mathrm{e}^{-\mathrm{kat}}\right)$

Where;

$\mathrm{C}$ : the concentration of lornoxicam in plasma at time $\mathrm{t}$

A: a constant coefficient or intercept

$\mathrm{k}_{\mathrm{el}}$ and $\mathrm{k}_{\mathrm{a}}$ : rate constants of elimination and absorption, respectively.

It should be mentioned that, the onecompartment model was selected after comparison with another three alternative models (one-compartment with lag time, twocompartment with and without lag time). The fitting of the data did not require incorporation of a lag time.

The plasma concentration versus time data after I.V. administration could best be described by a one-compartment IV-Bolus model with first-order elimination. The data were fit to a one-compartment model of the format:

$\mathrm{C}=\mathrm{A}\left(\mathrm{e}^{-\mathrm{kelt}}\right)$

Where;

$\mathrm{C}$ : the concentration of lornoxicam in plasma at time $\mathrm{t}$

A: a constant coefficient or intercept

$\mathrm{k}_{\mathrm{el}}$ : elimination rate constant.

Mean values of pharmacokinetic parameters are given in table 2. From the results it was found that, the three formulations showed almost similar pharmacokinetic parameters, except for $\mathrm{C}_{\max }$ which was lower in case of formulation $1(0.899 \mu \mathrm{g} / \mathrm{ml}$ compared to 1.144 and $1.248 \mu \mathrm{g} / \mathrm{ml}$ for formulation 2 and formulation 3 , respectively). The difference between any formulation and each of the other two formulations was statistically significant $(\mathrm{P}<0.05)$. The $\mathrm{C}_{\max }$ values of the buccal formulations were lower than that of I.V. lornoxicam $(3.024 \mu \mathrm{g} / \mathrm{ml}, \mathrm{P}<0.001)$. The AUC for formulation 2 and formulation 3 were higher than that of formulation 1 (5.621 and $6.275 \mu \mathrm{g} . \mathrm{h} \cdot \mathrm{ml}^{-1}$ compared to $4.291 \mu \mathrm{g} . \mathrm{h} \cdot \mathrm{ml}^{-1}$, $\mathrm{P}<0.05$ ) indicating a higher bioavailability, while that of I.V. lornoxicam was 7.262 $\mu$ g.h.ml ${ }^{-1}$. So, the bioavailability of lornoxicam from formulations 1,2 , and 3 was $59.09 \%$, $77.40 \%$, and $86.41 \%$, respectively. These results showed that lornoxicam formulated in different buccal patches was successfully delivered to the systemic circulation and had high absolute bioavailability values.

\section{Clinical evaluation}

Previous studies have evaluated oral lornoxicam as an analgesic for post-operative pain. For instance, studies evaluated oral lornoxicam at $8 \mathrm{mg}$ per day in the treatment of patients with post-operative pain following third molar extraction for a period of $24 \mathrm{hrs}^{18}$ and $72 \mathrm{hrs}^{19}$. These studies showed that the oral preparation is effective in treating moderate to 
Table 2: Pharmacokinetic parameters (mean) of lornoxicam in plasma of rabbits after I.V. and buccal administration of $2 \mathrm{mg}$ lornoxicam.

\begin{tabular}{|l|l|l|l|l||}
\hline $\begin{array}{c}\text { Pharmacokinetic } \\
\text { parameter }\end{array}$ & \multicolumn{1}{|c|}{ Formulation 1 } & \multicolumn{1}{|c||}{ Formulation 2 } & \multicolumn{1}{|c|}{ Formulation 3 } & \multicolumn{1}{c|}{ I.V. } \\
\hline $\mathrm{C}_{\max }(\mu \mathrm{g} / \mathrm{ml})$ & $0.899 \pm 0.051^{*, * *}$ & $1.144 \pm 0.046^{*, * * *}$ & $1.248 \pm 0.158^{*, * *}$ & $3.024 \pm 0.076$ \\
\hline $\mathrm{T}_{\max }(\mathrm{h})$ & $1.756 \pm 0.124$ & $1.807 \pm 0.245$ & $1.849 \pm 0.165$ & 0.000 \\
\hline $\mathrm{K}_{\mathrm{a}}\left(\mathrm{h}^{-1}\right)$ & $0.567 \pm 0.054$ & $0.547 \pm 0.047$ & $0.541 \pm 0.041$ & - \\
\hline $\mathrm{T}_{1 / 2 \mathrm{a}}(\mathrm{h})$ & $1.221 \pm 0.112$ & $1.267 \pm 0.147$ & $1.280 \pm 0.141$ & - \\
\hline $\mathrm{K}_{\mathrm{el}}\left(\mathrm{h}^{-1}\right)$ & $0.572 \pm 0.047$ & $0.559 \pm 0.023$ & $0.540 \pm 0.042$ & $0.417 \pm 0.033$ \\
\hline $\mathrm{T}_{1 / 2}(\mathrm{~h})$ & $1.213 \pm 0.145$ & $1.237 \pm 0.153$ & $1.283 \pm 0.142$ & $1.664 \pm 0.157$ \\
\hline $\mathrm{AUC}\left(\mu \mathrm{g} \cdot \mathrm{h}_{\mathrm{m}} \mathrm{ml}^{-1}\right)$ & $4.291 \pm 0.245^{* * * *}$ & $5.621 \pm 0.235^{* * *}$ & $6.275 \pm 0.145^{*, * *}$ & $7.262 \pm 0.371$ \\
\hline $\mathrm{CL} / \mathrm{F}\left(\mathrm{ml} \cdot \mathrm{min}^{-1} / \mathrm{kg}\right)$ & $0.466 \pm 0.176$ & $0.356 \pm 0.042$ & $0.319 \pm 0.042$ & $0.278 \pm 0.064^{\mathrm{a}}$ \\
\hline
\end{tabular}

$\mathrm{C}_{\max }$ : maximum concentration; $\mathrm{T}_{\max }$ : time of maximum concentration achieved after administration; $\mathrm{K}_{\mathrm{a}}$ : absorption rate constant; $\mathrm{t}_{1 / 2 \mathrm{a}}$ : absorption half-life; $\mathrm{K}_{\mathrm{el}}$ : elimination rate constant; $\mathrm{t}_{1 / 2}$ : elimination half-life; AUC: area under the lornoxicam concentration-time curve; $\mathrm{Cl} / \mathrm{F}$ : clearance, divided by bioavailabe fraction.

${ }^{a}$ In case of I.V. administration, this value represents the clearance $(\mathrm{Cl})$.

* $\mathrm{P}<0.05$ compared to other formulations.

${ }^{* *} \mathrm{P}<0.001$ compared to I.V. lornoxicam.

severe acute post-operative pain. When the post-operative analgesic efficacy of $8 \mathrm{mg}$ lornoxicam PO, IM and IV administration was evaluated, there was no difference in the analgesic effect between the different routes ${ }^{20}$. It was found to be as effective as $400 \mathrm{mg}$ ibuprofen $^{19}$ or $1000 \mathrm{mg}$ diflunisal ${ }^{21}$. None of the previous studies investigated the efficacy of buccal lornoxicam.

In the current study, a time-series analysis was undertaken to determine the efficacy (analgesic and anti-inflammatory activity) and safety of lornoxicam formulated in the three selected buccal patches among patients with post-operative pain and edema following maxillofacial operations versus the commercial piroxicam (Feldene Flash $^{\circledR}$ tablet). Feldene Flash $^{\circledR}$ was selected for comparison because it was the NSAID routinely used in the unit of maxillofacial surgery (in addition to the opioid drug Pethidine ${ }^{\circledR}$ ), and it belongs to the same class of lornoxicam (oxicams). In addition, this product is also administered sublingually, so it was the closest available product for comparison to buccal lornoxicam. Table 3 shows the mean visual analogue scale pain scores (PS) over the study period starting from day-1, i.e. the night of the operation day, to day-4 after using the buccal patches and the classical oral preparation in patients. In general, there has been a progressive decline in the level of pain within the days of therapy for both patches and oral preparation. Application of the analysis of variance (ANOVA) to test the pain score variability with time yielded a highly significant $\mathrm{F}$ value $\left(\mathrm{F}=11.25^{* *}\right)$ for formulation $1,\left(\mathrm{~F}=14.38^{* *}\right)$ for formulation 2 , $\left(\mathrm{F}=8.27^{* *}\right)$ formulation 3 , and the tablets $((\mathrm{F}=$ $4.91 * *)$.

When the means were subjected to the least significant difference test, results were significant between the first day scores and those obtained on the next 3 days as shown in table 3.

Comparison among the results in table 3 revealed also that subjects treated with buccal formulations showed a trend towards a greater pain score reduction (at the end of the followup period) compared with those treated with the tablets. Statistical analysis by the ANOVA test showed that differences between them in pain score reduction was highly significant $(\mathrm{F}=$ $\left.32.78^{* *}\right)$. Application of the least significant difference test to determine which of the formulations differs significantly from the other formulations indicated that formulation 1 differs significantly from each of the other two formulations and also from the tablets. Comparison between formulation 2 and formulation 3 indicated that formulation 2 differs significantly from formulation 3 . Also 
Table 3: Effect of various lornoxicam buccal patches and Feldene Flash ${ }^{\circledR}$ tablets on average pain score and mean swelling thickness in patients.

\begin{tabular}{|c|c|c|c|c|c|c|c|c|c|c|c|}
\hline \multirow{3}{*}{ Formulation } & \multirow{3}{*}{$\begin{array}{c}\text { Clinical } \\
\text { parameter }\end{array}$} & \multicolumn{5}{|c|}{ Score level } & \multicolumn{5}{|c|}{ Least significance difference test } \\
\hline & & \multicolumn{5}{|c|}{ Days } & & & & & \\
\hline & & 0 & 1 & 2 & 3 & 4 & $\begin{array}{c}1^{\text {st }} \text { vs. } 2^{\text {nd }} \\
\text { day }\end{array}$ & $\begin{array}{c}1^{\text {st }} \text { vs. } 3^{\text {rd }} \\
\text { day }\end{array}$ & $\begin{array}{c}1^{\text {st }} \text { vs. } 4^{\text {th }} \\
\text { day }\end{array}$ & $\begin{array}{c}3^{\text {rd }} \text { vs. } 4^{\text {th }} \\
\text { day }\end{array}$ & $\mathrm{LSD}_{0.05}$ \\
\hline \multirow{2}{*}{ Formulation 1} & PS & - & 3.70 & 2.50 & 1.90 & 1.10 & $1.20 *$ & $1.80 * *$ & $2.60 *$ & 0.80 & 0.94 \\
\hline & $\mathrm{ST}(\mathrm{cm})$ & 1.67 & 2.87 & 2.53 & 2.32 & 2.03 & - & - & - & - & - \\
\hline \multirow{2}{*}{ Formulation 2} & PS & - & 3.40 & 2.30 & 1.80 & 1.30 & $1.10 * *$ & $1.60 * *$ & $2.10 * *$ & 0.50 & 0.68 \\
\hline & ST $(\mathrm{cm})$ & 1.58 & 2.62 & 2.33 & 2.00 & 1.66 & 0.29 & 0.62 & $0.96 * *$ & 0.34 & 0.69 \\
\hline \multirow{2}{*}{ Formulation 3} & PS & - & 3.70 & 2.80 & 2.50 & 2.00 & $0.90^{*}$ & $1.20 * *$ & $1.70 * *$ & 0.50 & 0.71 \\
\hline & $\mathrm{ST}(\mathrm{cm})$ & 1.62 & 1.74 & 1.30 & 0.96 & 0.66 & 0.44 & $0.78 * *$ & $1.08 * *$ & 0.30 & 0.50 \\
\hline \multirow{2}{*}{ Feldene Flash $®$} & PS & - & 3.90 & 3.10 & 2.70 & 1.90 & $0.80 *$ & $1.20 * *$ & $2.00 * *$ & $0.80 *$ & 0.71 \\
\hline & $\mathrm{ST}(\mathrm{cm})$ & 1.47 & 1.59 & 1.37 & 1.13 & 0.95 & 0.22 & $0.46^{*}$ & $0.64 * *$ & 0.18 & 0.44 \\
\hline
\end{tabular}

$*=\mathrm{P}<0.05 \quad * *=\mathrm{P}<0.01$

ST: mean swelling thickness $(\mathrm{cm})$.

Day-0 is the pre-operative day; day-1 is the day of operation starting 4 hrs after the application of gel.

there was a highly significant difference between formulation 2 and Feldene Flash $^{\circledR}$ tablets. Similarly, the difference between formulation 3 and Feldene Flash ${ }^{\circledR}$ was highly significant (results of LSD test are shown in table 4).

Table 4: Least significant difference between mean pain score (PS) of different formulations $\left(\mathrm{F}=32.78^{* *}\right)$.

\begin{tabular}{|l|c|c|c|}
\hline \multicolumn{1}{|c|}{ Formulation } & $\begin{array}{c}\text { Formulat- } \\
\text { ion 1 }\end{array}$ & $\begin{array}{c}\text { Formulat- } \\
\text { ion 2 }\end{array}$ & $\begin{array}{c}\text { Formulat- } \\
\text { ion 3 }\end{array}$ \\
\hline Formulation 1 & - & - & - \\
\hline Formulation 2 & $1.00^{* *}$ & - & - \\
\hline Formulation 3 & $1.45^{* *}$ & $0.45^{*}$ & - \\
\hline Feldene Flash $^{\circledR}$ & $2.10^{* *}$ & $1.10^{* *}$ & $0.65^{* *}$ \\
\hline
\end{tabular}

$*=\mathrm{P}<0.05 \quad * *=\mathrm{P}<0.01 \quad \mathrm{LSD}_{0.05}=0.43$

Table 3 also shows the mean value for swelling thickness (ST) measured at baseline (day-0) and at the 4 days following operation. Results revealed that there was no significant change in the mean swelling thickness along the 4 study days for formulation $1 \quad(F=0.67)$ indicating there was no effective reduction in swelling. On the other hand, formulation 2 and formulation 3 were effective in reduction of the swelling over the study days $\left(\mathrm{F}=3.00^{*}\right.$ and $7.21^{* *}$, respectively). Feldene Flash ${ }^{\circledR}$ was also effective in reduction of the swelling ( $\mathrm{F}=$ $3.32 *)$. The ST values were also subjected to the LSD test (except formulation 1 because it did not show any reduction of ST) and it was found that the differences were significant between the first day and each of the following 3 days for the other formulations, indicating effective reduction of edema with time progression.

However, on comparing the ST on day- 0 (pre-operative) with that on day-1, it was found that the difference was not significant in case of formulation 3 only, indicating that this formulation was effective in preventing the appearance of edema $(\mathrm{P}=0.6676>0.05)$. The same was observed for the tablets $(\mathrm{P}=$ $0.5919>0.05)$. In case of formulation 2 and formulation 3 , the difference between day-0 and day- 1 was highly significant indicating that a significant swelling has occurred on the first day and that these formulations were not effective in preventing the appearance of edema $(\mathrm{P}=0.0182<0.05$ and $\mathrm{P}=0.0053<0.01$ for formulation 1 and formulation 2, respectively).

So, formulation 1 was considered ineffective for prevention or reduction of edema, formulation 2 was effective in reduction of edema only, while formulation 3 and Feldene Flash $^{\circledR}$ effectively prevented appearance of edema on day-1 and also reduced the slight edema that appeared on that day over the rest of study days.

Statistical analysis by the ANOVA test was carried out to compare the effectiveness of different formulations on ST (formulation 1 was not included, as it neither prevented nor 
reduced the swelling significantly). The statistical analysis showed that differences between formulations in ST reduction was significant $\left(\mathrm{F}=3.16^{*}\right)$. Application of the least significant difference test (LSD) to determine which of the formulations differs significantly from the other formulations indicated that there was no significant difference between formulation 3 and Feldene Flash ${ }^{\circledR}$ regarding this effect, but the difference between Formulation 2 and Feldene Flash $^{\circledR}$ was significant (table 5). This suggests that formulation 3 was equally effective to the orally administered commercial oxicam product (Feldene Flash ${ }^{\circledR}$ tablets).

Table 5: Least significant difference between mean swelling thickness (ST) of different formulations $\left(\mathrm{F}=3.16^{*}\right)$.

\begin{tabular}{||c|c|c|}
\hline \hline Formulation & Formulation 2 & Formulation 3 \\
\hline Formulation 2 & - & - \\
\hline Formulation 3 & 0.28 & - \\
\hline Feldene Flash & $0.56 *$ & 0.28 \\
\hline$*=\mathrm{P}<0.05 \quad * *=\mathrm{P}<0.01 \quad \mathrm{LSD}_{0.05}=0.44$
\end{tabular}

Figure 4 shows the tenderness level with time for the tested formulations. Each formulation was tested on 10 patients. At the initial stage (day-1), $50 \%$ of patients treated with formulation 1 experienced severe tenderness, whereas $30 \%, 50 \%$ and $40 \%$ of patients were recorded for formulations 2 and 3 and Feldene Flash ${ }^{\circledR}$ tablets, respectively. By day-2, no patient of those receiving formulation 2 reported severe tenderness, only 3 patients had severe tenderness in formulation 1 group, and only one patient in formulation 3 group, while 2 patients maintained severe tenderness on day- 2 in the Feldene Flash ${ }^{\circledR}$ group. By day3 , none of the patient had severe tenderness except for one patient in formulation 1 group. With time progression, the shift from the moderate to mild level was notable for both patches and tablets, by the end of study period (day-4), the percentage of patients having no tenderness at all was $10 \%, 40 \%$, and $10 \%$ for formulation 1 , formulation 3 , and the tablets, respectively, which is reflective of a high rate of improvement. For formulation 2, $80 \%$ of the patients had mild tenderness and 20\% had moderate tenderness by day- 4 , indicating less efficiency of this formulation in relieving tenderness.

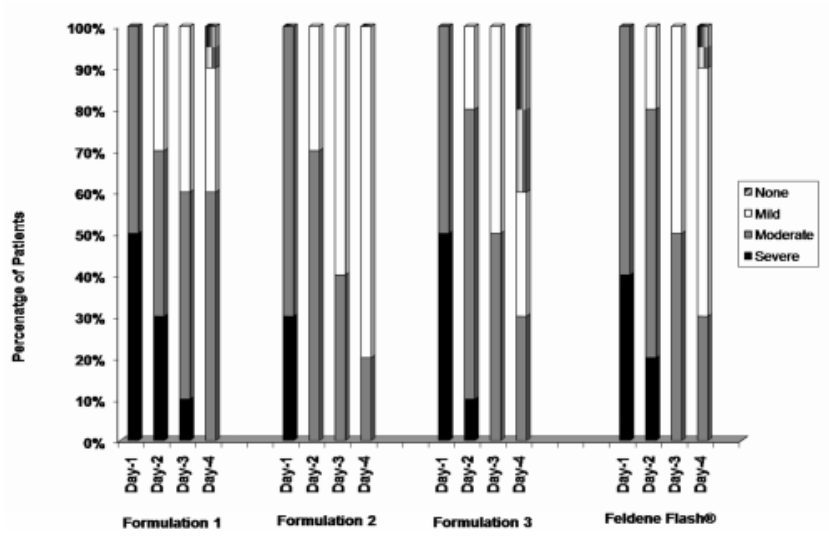

Fig. 4: Tenderness level following application of different lornoxicam formulations.

To compare the effect of the different formulations on reducing the tenderness level, it was considered that when the level decreased by two grades (i.e. from severe to mild or from moderate to none), that this was an effective reduction and the percentage of patient showing effective reduction from each group were compared by the Student's $t$-test. The findings revealed no significant differences $(\mathrm{P}>$ $0.1)$ in the tenderness reduction levels of formulations 1 and 2 and the tablets indicating that, these buccal patches are equally effective to the oral tablets in improving tenderness level. However, the difference in change of tenderness levels during the observation interval was statistically significant between formulation 3 and each of the other formulations $(\mathrm{P}<0.01$ for formulatoin 3 versus formulation 1 or formulation $2, \mathrm{P}<0.05$ for formulation 3 versus the tablets), implying that formulation 3 was more effective in relieving tenderness.

Regarding toleration, the buccal patches were well tolerated but $43 \%$ of patients complained of mild bitter taste of the buccal patches but there were no complaints of gastrointestinal side effects which are commonly related to the oral administration of the drug.

\section{Conclusion}

The in-vivo results of buccal administration of lornoxicam to rabbits showed that lornoxicam formulated in different buccal patches was successfully delivered to the 
systemic circulation and had a high bioavailability, which suggests that the drug would exert its action through both systemic and local effects. Overall, the results obtained from the in-vitro release and in-vitro skin permeation in part I of this study ${ }^{14}$ were in accordance with the clinical response in patients, as NaCMC patch (which proved high clinical effectiveness) showed the highest drug release rate of the drug in-vitro and more drug permeation through rabbit buccal mucosa. In addition, this patch had high bioadhesive characteristics.

These results recommend that the buccal administration of lornoxicam formulated especially, in $\mathrm{Na} \mathrm{CMC}$ patch (formulation 3) is a promising, safe alternative to the oral administration for the management of postoperative pain and edema following maxillofacial operations.

\section{REFERENCES}

1- L. L. Christrup, C. B. Christensen, G. J. Früs and A. Jorgensen, "Improvement of buccal delivery of morphine using the prodrug approach", Int. J. Pharm., 154, 157 (1997).

2- K. Tsutsumi, Y. Obata, K. Takayama, T. Loftsson and T. Nagai, "Effect of codliver oil extract on the buccal permeation of ergotamine tartrate", Drug Dev. Ind. Pharm., 24, 757 (1998).

3- J. Lee and I. W. Kellaway, "Combined effect of oleic acid and polyethylene glycol 200 on buccal permeation of [D$\left.\mathrm{Ala}^{2}, \mathrm{D}-\mathrm{Leu}^{5}\right]$ enkephalin from a cubic phase of glyceryl monooleate", Int. J. Pharm., 204, 137 (2000).

4- B. Albertini, N. Passerini, M. Di Sabatino, D. Monti, S. Burgalassi, P. Chetoni and L. Rodriguez, "Poloxamer 407 microspheres for orotransmucosal drug delivery. Part I: Formulation, manufacturing and characterization", ibid., 399, 71 (2010).

5- N. Hassan, M. Ali and J. Ali, "Development and evaluation of novel buccoadhesive wafers of nimodipine for treatment of hypertension", Drug Deliv., 17, 59 (2010).

6- G. Campisi, C. Paderni, R. Saccone, O. Di Fede, A. Wolff and L.I. Giannola, "Human buccal mucosa as an innovative site of drug delivery", Curr. Pharm. Des., 16, 641 (2010).

7- M. J. Rathbone, B. K. Drummond and I. G. Tucker, "The oral cavity as a site for systemic drug delivery", Adv. Drug. Del. Rev., 13, 1 (1994).

8- J. Lee and Y. W. Choi., "Enhanced exvivo buccal transport of propranolol: evaluation of phospholipids as permeation enhancers", Arch. Pharm. Res., 26, 421 (2003).

9- R. A. Thakur, B. B. Michniak and V. M. Meidan, "Transdermal and buccal delivery of methylxanthines through human tissue in-vitro", Drug Dev. Ind. Pharm., 33, 513 (2007).

10- N. Hassan, A. Ahad, M. Ali and J. Ali, Expert Opin. Drug Deliv., 7, 97 (2010).

11- N. A. Nafee, F. A. Ismail, N. A. Boraei and L.M. Mortada, "Mucoadhesive buccal patches of miconazole nitrate: in-vitro/invivo performance and effect of ageing", Int. J. Pharm., 264, 1 (2003).

12- Z. Yifan, Z. Dafang, S. Dayong, G. Yingjie, C. Xiaoyan and Z. Hui, "Lornoxicam pharmacokinetics in relation to cytochrome P450 2C9 genotype", Br. J. Clin. Pharmacol., 59, 14 (2005).

13- S. Radhofer - Welte, P. dittrich, M. Simin and P.E. Branebjerg, "Comparative bioavailability of lornoxicam as single doses of quick-release tablet, standard tablet and intramuscular injection: a randomized, open-label, crossover phase I study in healthy volunteers", Clin. Drug. Invest., 28, 345 (2008).

14- F. Habib, M. Abdel Azeem, G. Fetih and M. Safwat, "Mucoadhesive buccal patches of lornoxicam: I- Development and invitro characterization", Bull. Pharm. Sci., Assiut Univ., 33, 59 (2010).

15- Y. H. Kim, H. Y. Ji, E-S. Park, S-W. Chae and H. S. Lee, "Liquid chromatographyelectrospray ionization tandem mass spectrometric determination of lornoxicam in human plasma", Arch. Pharm. Res., 30, 905 (2007).

16- E. A. Taha, N. N. Salama and L. E. Abdel Fattah, "Stability-indicating chromatographic methods for the determination of some oxicams", J. AOAC Int., 87, 366 (2004). 
17- M. A. Attia, I. El-Gibaly, S. E. Shaltout and G. N. Fetih, "Transbuccal permeation, anti-inflammatory activity and clinical efficacy of piroxicam formulated in different gels", Int. J. Pharm., 276, 11 (2004).

18- P. E. Hall, S. Derry, R. A. Moore and H. J. McQuay, "Single dose oral lornoxicam for acute postoperative pain in adults", Cochrane Database of Systematic Reviews, Issue 4, Art. No.: CD007441. DOI: 10 (2009).

19- F. D. Lustenberger, K. W. Grätz and T. S. Mutzbauer, "Efficacy of ibuprofen versus lornoxicam after third molar surgery: a randomized, double-blind, crossover pilot study", Oral Maxillofac. Surg., 15, 57 (2011).
20- I. Kara, L. Yavuz, B. G. Ceylan and F. Eroğlu, "The effect of three different lornoxicam administrations on postoperative analgesia", Agri., 20, 23 (2008).

21- Z. O. Pektas, M. Sener, B. Bayram, T. Eroglu, N. Bozdogan, A. Donmez, G. Arslan and S. Uckan, "A comparison of pre-emptive analgesic efficacy of diflunisal and lornoxicam for postoperative pain management: a prospective, randomized, single-blind, crossover study", Int. J. Oral Maxillofac. Surg., 36, 123 (2007). 